\title{
A Preliminary Investigation of Malaysian Student's Daily Use of Mobile Devices as Potential Tools for STEM in a Local University Context
}

\author{
https://doi.org/10.3991/ijim.v12i2.8015 \\ Shamsul Arrieya Ariffin, Salman Firdaus Side, Mohd Fadhil Harfiez Mutalib \\ Sultan Idris Education University, Tanjung Malim, Malaysia \\ shamsuleupsi.edu.my
}

\begin{abstract}
Mobile learning is a fairly new approach to the educational paradigm where learning is concerned. The usage of mobile learning may also be extended to various fields including Science, Technology, Engineering, and Mathematics (STEM). As Malaysia is lagging behind in STEM, this research is conducted to study preliminary information concerning mobile learning in a local university context, particularly, STEM. The method for this research is a descriptive survey. The results indicate that students already have some skills in using mobile phones, particularly multimedia skills, which can be applied to STEM.
\end{abstract}

Keywords-STEM, mobile learning, mobile devices, education

\section{$1 \quad$ Introduction}

Information and Communication Technologies (ICT) can introduce many interesting approaches to the current learning field. Research on Local Cultural Studies also affirms the advantages of student-generated multimedia content through mobile learning [1]. Furthermore, mobile learning can be extended to the context of other subjects, such as Science, Technology, Engineering and Mathematics (STEM), which need further understanding including [23] student-generated multimedia activities. This also coincides with the $11^{\text {th }}$ Malaysian Plan [14] (RMK11) to foster local content development in the country [15]:

"Localised and customised content in areas such as agriculture, business, education and health, will be developed to help specific community segments to access information and add value in their daily lives. Such content will be delivered through technologies that are simple and easily accessible such as mobile platforms, which allow greater outreach to the population."

The STEM Initiative in the Malaysia Education Blueprint 2013-2025 indicates the seriousness of the Malaysian government to equip students with the necessary skills to meet the science and technology challenges and to ensure that Malaysia has a sufficient number of qualified STEM graduates who are currently lacking [12]. 


\subsection{Mobile Learning}

Mobile learning in Asia is also considered to be a fairly new approach to access education as it enables learners to pursue their studies according to their own scheduled time. Mobile Learning is also free from fixed class times, which enables learning at all times and in all places - during breaks, before or after shifts, at home, or on the go - because of the portability of mobile devices [7]. Based on previous research, the results of six mobile learning projects that took place in several developing countries in Asia - the Philippines, Mongolia, Thailand, India, and Bangladesh - indicate that the developing nations from the region could become global leaders in the educational uses of mobile learning [13].

Mobile learning facilitates the design of authentic learning, meaning learning that targets real-world problems and involves projects that are of interest to the learner [9]. Also, theoretically, mobile phones enable students to customize the transfer of, and access to information in order to build on their skills and knowledge and to meet their own educational goals. Thus, mobile learning approaches make learner-centered learning possible and empower students. This phenomenon of using mobile devices makes learning more effective and teaching related to mobile learning and Malaysia is increasing day by day through the usage of mobile learning in education.

\subsection{Mobile Learning for STEM}

Mobile learning (e.g., mobile devices, mobile phones, and laptops/computers) is a fairly new approach to the educational paradigm in terms of learning. Mobile Learning is the process involving conversations across multiple contexts among people and personal interactive technologies [22]. The implementation of STEM in Malaysian education can benefit the students in the fields of science, technology, engineering, and mathematics. The focus of STEM is driving ICT in the economy based on knowledge through innovation and productivity, which, in turn, will increase competition and wealth. Integrative STEM education is about the teaching and learning of one or more subject areas in schools or any other educational institution. Integrative STEM education is defined as general education that focuses on preparing citizens to function in a science and technology-rich society [13]. STEM is the purposeful integration of various disciplines to solve real-world problems that involve all four (4) science, technology, engineering, and mathematics - as one unit. In this study, STEM could be enhanced through the use of mobile devices by students $[11,12,21]$.

\subsection{Opportunities in STEM as offered by student-generated multimedia for the generation of local content}

Student-generated activities with experiential learning encourage students to actively participate instead of sitting passively [6]. Likewise, despite the challenges in the Malaysian context, there are opportunities for student content-generated activities [1]. Nowadays, students are more knowledgeable and tech-savvy in utilizing mobile phones. Students in Malaysia are becoming more advanced in utilizing the functions 
of mobile devices for learning activities. In addition, student-generated content should be explored for other non-cultural subjects that include STEM subjects [1]. STEM subjects have not been well received by students as they are not motivated to learn the subjects. Therefore, there is potential to explore STEM associated subjects in Malaysia through the use of mobile learning for student-generated content.

In Malaysia, the context of local content on STEM can be referred to the Education Philosophy as "emphasizing the strengthening of the quality of STEM education to develop the human capital that is knowledge, skilled, virtuous, creative and competitive." The Malaysian Development Education Plan 2013-2025 placed STEM as an important agenda issue for the transformation of the young generation for the $21^{\text {st }}$ century. This shows how important STEM is in education to transform education into a better future [12]. The Malaysia Education Blueprint 2013-2015 (2015) stated that among the factors leading to the decline in enrolment and the quality of student outcomes in STEM are the limited awareness about STEM, which includes difficulty in understanding STEM, content-heavy curriculum, inconsistent quality of teaching and learning, and limited and outdated infrastructure [12]. By integrating face-to-face ICT instruction, deploying new instructional strategies and pedagogical approaches, utilizing adaptive learning software to learn at their own pace, and through their preferred learning style, these issues can be overcome.

STEM develops students' interest through new learning system approaches and enhanced curriculum through the use of mobile devices. However, based on the personal observation of the researcher, Malaysian students, mostly from Sultan Idris Education University, used their mobile phone more for social media rather than to learn or explore new technology [1]. The issue here is due to the lack of the awareness to explore mobile learning and knowledge about the latest technology among students.

\subsection{Lack of Local Content}

In Malaysia, in particular, and Asia, in general, although there is a high penetration of mobile devices among the population, there is a lack of local content to support mobile learning [19]. The majority of the available mobile content is supplied by English-speaking countries, notably the USA and the UK; thus, making the content foreign and unsuitable for students, and, furthermore, discouraging the production of domestic content. The interviews conducted with six experts from the Malaysian mobile industry revealed a number of challenges to providing local content in Malaysia, including a lack of mobile content, low interest in developing content for mobile learning), and the narrow market for local content in Malaysia [2].

The lack of local digital content in Malaysia has a particularly negative impact on students studying their subjects through local content. Introducing up-to-date mobile technologies into their learning could enhance the level of interest in what might otherwise be viewed as dull subject matter that is irrelevant to the current technological times. Given the very high ownership of mobile phones among Malaysian university students, it is reasonable to expect students to generate their own multimedia content using their mobile devices [8]. Furthermore, the mobile phones are mostly reputable 
brands, such as Nokia and Sony Ericsson [20]. Students usually only require the multimedia functions provided by their mobile phones, such as photo, video, and audio recording capabilities, to create content. By encouraging student-generated content, students are introduced to a relatively modern approach to learning these subjects that simultaneously creates more local content and reduces the digital content gap in Malaysian institutions.

The globalization of cultural values as dictated by the US via media platforms like the Internet, and entertainment, such as movies and television, can dominate content production in developing countries; for example, the videos for the T2T mobile learning project in the Philippines were narrated with an American accent, and local students found the content difficult to understand [5]. Meanwhile, the lack of local content in Malaysia is another serious challenge that has received the attention of government ministers. The Malaysian government supported this statement by initiating the digital content development program [21]. Despite government efforts, the initial concern persists, that is, foreign content, still impedes the progress of local content development in Malaysia [2]. This lack of local content in subjects, including STEM, has yet to be addressed [1].

\section{Methodology}

This preliminary study used descriptive surveys. These instruments were developed [18] based on local cultural studies for mobile learning for the Malaysian context [1] but applied to STEM

Descriptive Surveys: To support the focus group discussions, a survey was used which was divided into sections. The sections comprised introduction and background, experience in using mobile devices, ethical experience in using mobile devices, and feedback for the survey. Additionally, a Likert scale was adopted for the descriptive statistics, while considering the mean from lowest to highest for a likelihood from 1 to 5 .

For this research study, Sultan Idris Education University or Universiti Pendidikan Sultan Idris (UPSI), a local education university that is the second oldest institution in Malaysia, and located in Tanjung Malim, Perak, Malaysia, was selected. The respondents were degree students from the five (5) different courses comprising the main focus in this research. For the questionnaire, a total of 127 students (aged 19-25) from five (5) classes - two classes come from the same course. They were asked to answer based on their experience and understanding of using mobile learning for STEM. In this study, the students used their own mobile devices [10], such as mobile phone, for the video project for their STEM subjects.

\subsection{Questionnaire Format}

The questionnaire consisted of three (3) sections comprising personal information and preferences, daily experience of using mobile phones, and formal learning experi- 
ence with mobile phones. The questionnaire was uploaded to google forms and answered by 127 students.

\subsection{Likert Scale}

The Likert scale is one of the most widely used scaling responses in survey research. In this research, the scale was adopted for the descriptive statistics while considering the mean from lowest to highest in the likelihood from 1 to 5 . When responding to a Likert item, the respondents specify their level of agreement or disagreement with a symmetric agree-disagree scale for a series of statements. Below is the list of questions used based on the Likert Scale. The questions asked their agreement concerning various issues and to identify the likeliness of that issue. As for the calculation of the scale, the assumptions were derived from the data, which were calculated to determine the mean of each question. The assumptions are shown in Table 1.

Table 1. Scale assumption for calculation of the mean

\begin{tabular}{|l|c|}
\hline \multicolumn{1}{|c|}{ Scale } & Value (Y) \\
\hline Never & 1 \\
\hline Rarely & 2 \\
\hline Sometimes & 3 \\
\hline Regularly & 4 \\
\hline Always & 5 \\
\hline
\end{tabular}

By using the assumption, the mean formula for this research is as shown in figure 1 , which is derived from the average formula.

$$
\begin{gathered}
\mu=[P(X) * Y] / \mathrm{N} \\
\mu=\text { Mean/Average } \quad \begin{array}{c}
\mathrm{Y}=\text { Scale Value } \\
\mathrm{N}=\text { Question }
\end{array} \quad \mathrm{X}=\text { Tssue }
\end{gathered}
$$

Fig. 1. The formula for the Mean

\section{$3 \quad$ Findings}

\subsection{Pre-Existing Attitudes and Experience of mobile learning For STEM in a Local University}

Descriptive information on the respondents' information: There were 127 responses comprising 45 male (35.4\%) and 82 female (64.6\%) students. The students were from the Faculty of Arts, Computing and Industry Creative, and the Faculty of Science and Mathematics from the University of Education Sultan Idris (Fig. 2).

Descriptive information on the operating system of the mobile devices: The number of students using mobile phones with the Android operating system software is $107(84.3 \%)$; Symbian 2 (1.6\%); Windows software 4 (3.1\%); and Apple 33 
(26\%). This indicates that the Android phone is the most popular operating system used by students (Fig. 3).

Descriptive information for the mobile devices brand: In terms of the brand for the mobile phone hardware, Samsung users total 47 (37\%); iPhone users 36 (28.3\%); for Lenovo 26 (20.5\%); ASUS 13 (11.1\%); and, for Nokia, 9 (7.1\%) students. This indicates that Samsung surpassed iPhone in terms of the brand of mobile phones (Fig. 4).

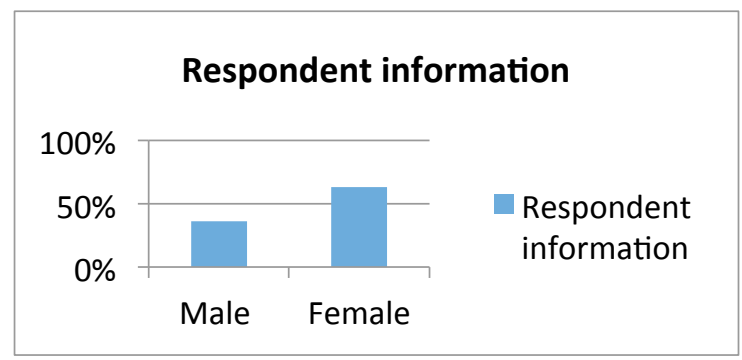

Fig. 2. Percent of gender

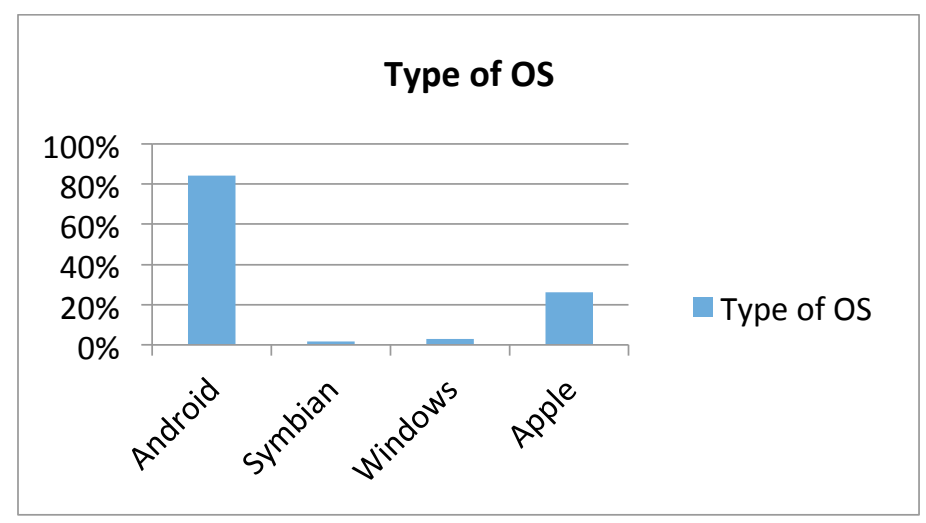

Fig. 3. Type of OS

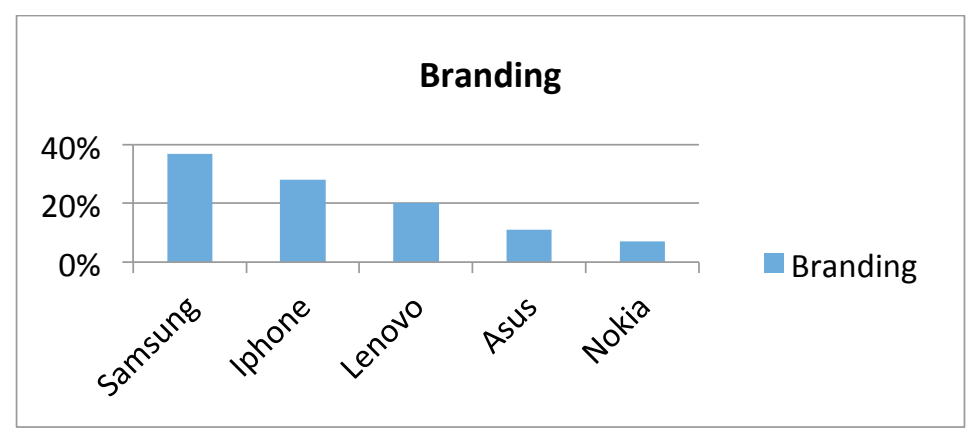

Fig. 4. Branding 
Descriptive information on mobile devices popular software: Ten popular apps are installed and used on mobile phones. According to the students the highest ranked software is WhatsApp with $124(97.6 \%)$, YouTube is second with $113(89 \%)$, Facebook is third with $111(87.4 \%)$, fourth is the Camera with $111(87.4 \%)$, fifth is Gmail with $109(85.8 \%)$, the Calculator is sixth with $108(85 \%)$, SMS is seventh with 104 (81.9\%), the Google Chrome Browser is eighth with 100 (78.7\%), the MP3 Player is ninth with $90(70.9 \%)$ and Google Maps is tenth with $88(69.3 \%)$. This indicates that social media - WhatsApp, YouTube, and Facebook - have the highest popularity for usage amongst the students (Fig. 5).

Descriptive information on affordable prices of mobile devices: In terms of mobile phones that students can afford, 9 (7.1\%) own phones priced below RM 200; $30(23.6 \%)$ own phones ranging from RM 201 to RM 500; 47 (37\%) own phones ranging from RM 501 to RM 1000; 31 (24.4\%) possess phones costing RM 1000 to RM 2000; and 10 (7.9\%) could afford phones costing RM 2000 or more. This indicates that most students cannot afford expensive mobile devices (Fig. 6).

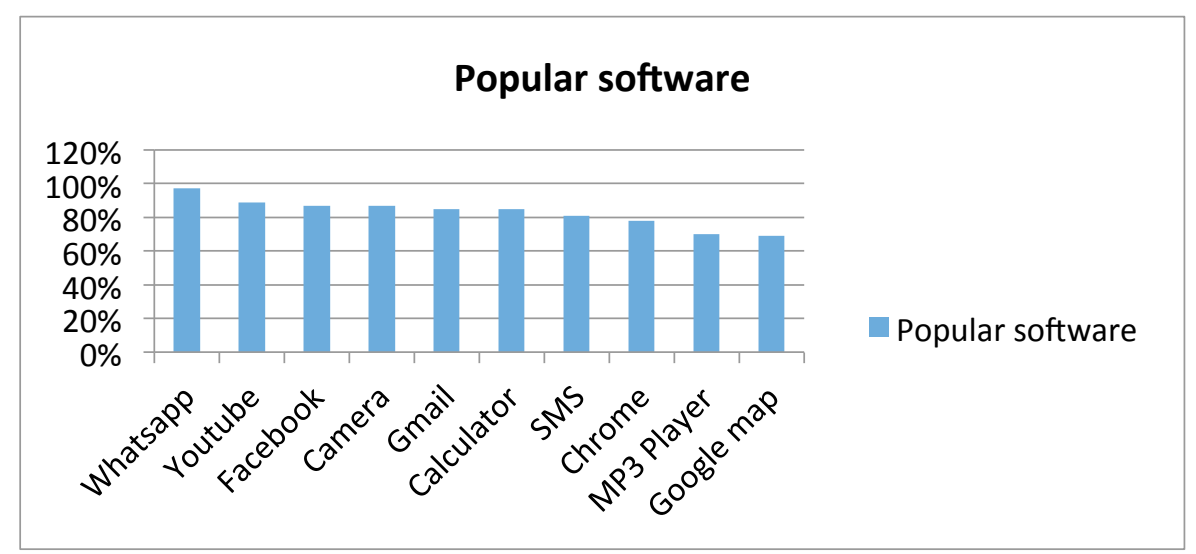

Fig. 5. Popular software

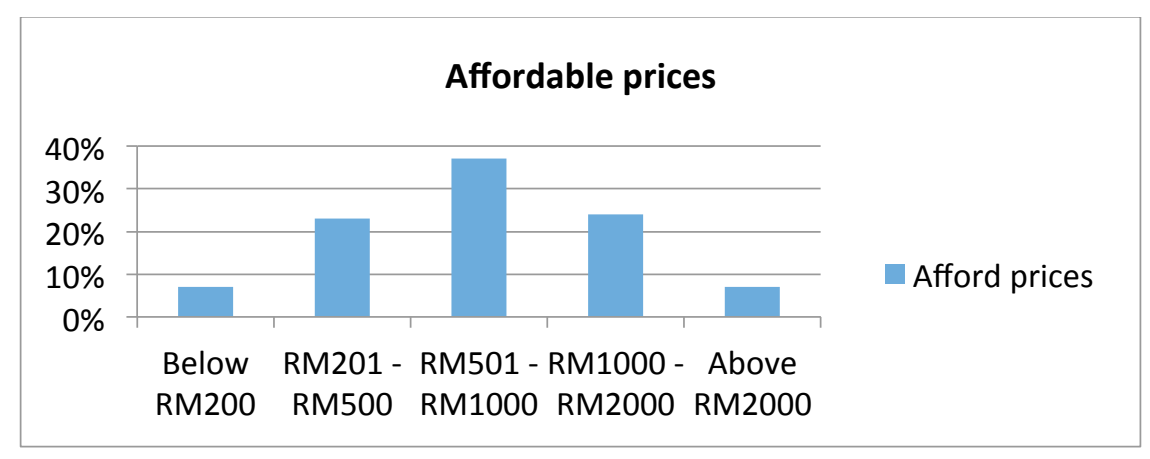

Fig. 6. Affordable prices 
Descriptive information concerning how students learned to use mobile devices for learning: The number of students who used mobile devices for self-regulated learning is $105(82.7 \%)$. Students who learned to use mobile devices for learning through friends total $82(64.6 \%)$. Students who learned how to use mobile devices from family number $38(29.9 \%)$. Students who learned how to use mobile devices from teachers for learning are $40(31.5 \%)$ and others 25 (19.7\%) (Fig. 7).

Descriptive information for students existing ethical practices: Students who were previously self-regulatory in practicing mobile ethics numbered 77 (60.6\%); from school rules 24 (18.9\%); from university 30 (23.6\%); from home 17 (13.4\%); and do not know 31 (24.4\%). This indicates a certain lack of awareness of ethical practices when using mobile devices (Fig. 8).

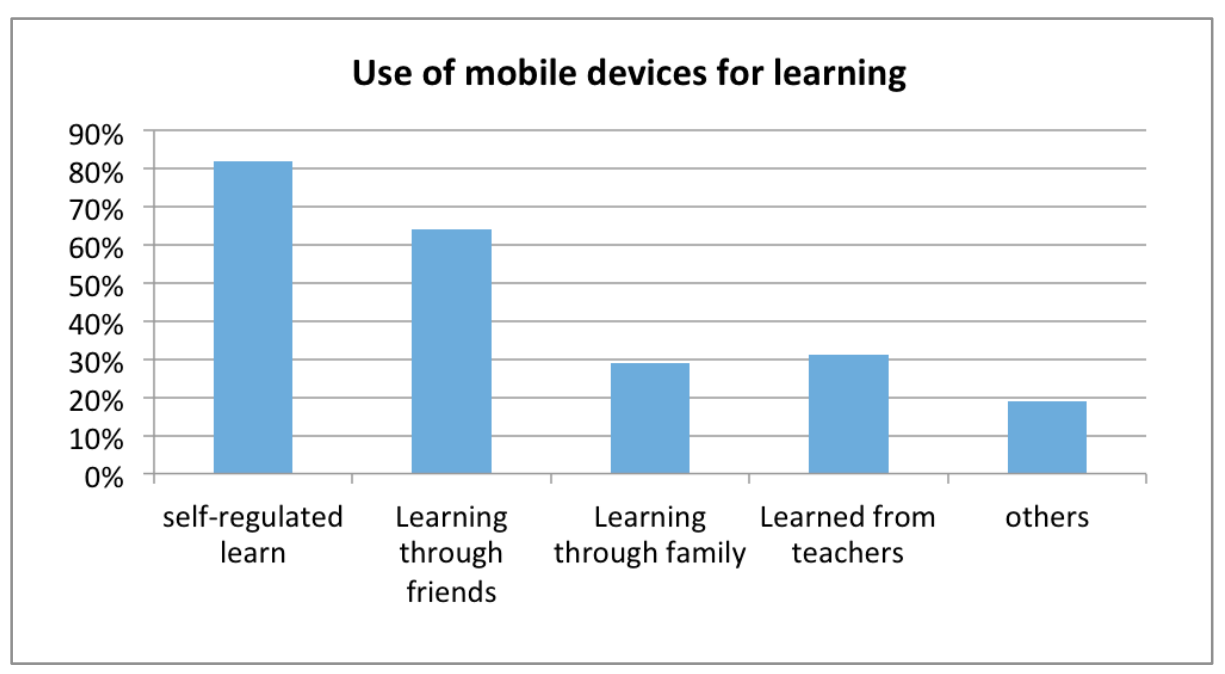

Fig. 7. Use of mobile devices for learning

\section{Practice mobile ethics}

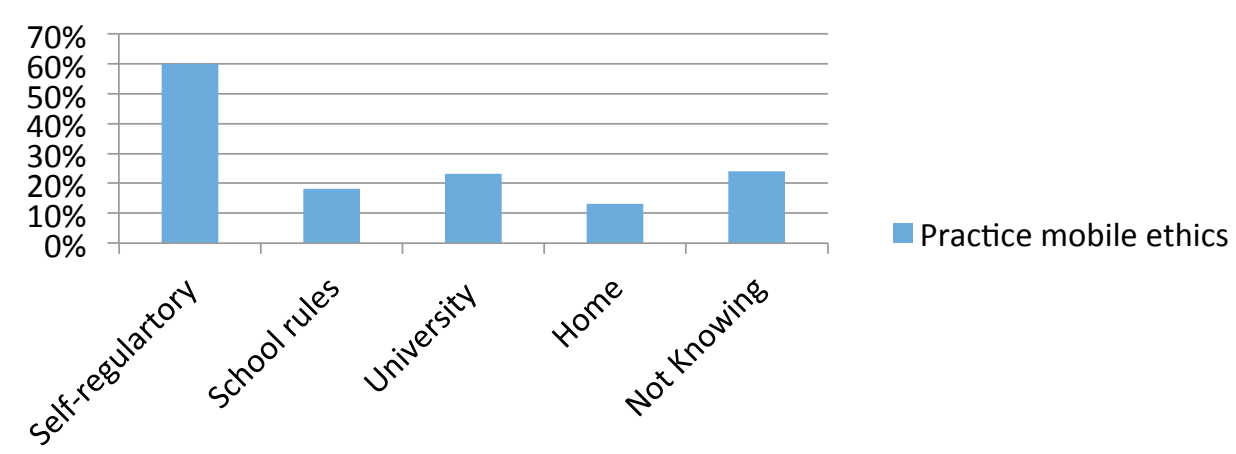

Fig. 8. Practice mobile ethics 
Descriptive information about definition of mobile learning: Before studentgenerated activities, those who answered 'yes' to using the mobile device for sharing information numbered 120 out of 127 (94\%); for answering quizzes, 108 of 127 (85\%); games and applications, 94 (74\%); for finding information, 119 (94\%); for multimedia recording during class, $85(67 \%)$; and multimedia recording outside of class, 91 (72\%) (Fig. 9).

Statistics for mobile phone use during informal learning: On average, to record audio has an average of 2.80 , to record video has an average of 2.84 , to take photo has an average of 3.42 , to edit video has an average of 2.45 , to edit audio has an average of 2.31, and to edit photo has an average of 3.07 ()Table 2 .

Statistics about mobile phone use during formal learning: On average, to record audio has an average of 2.78, to record video has an average of 2.84, to take photo has an average of 3.45 , to edit video has an average of 2.46 , to edit audio has an average of 2.37 , and to edit photo has an average of 2.96 (Table 3 ).

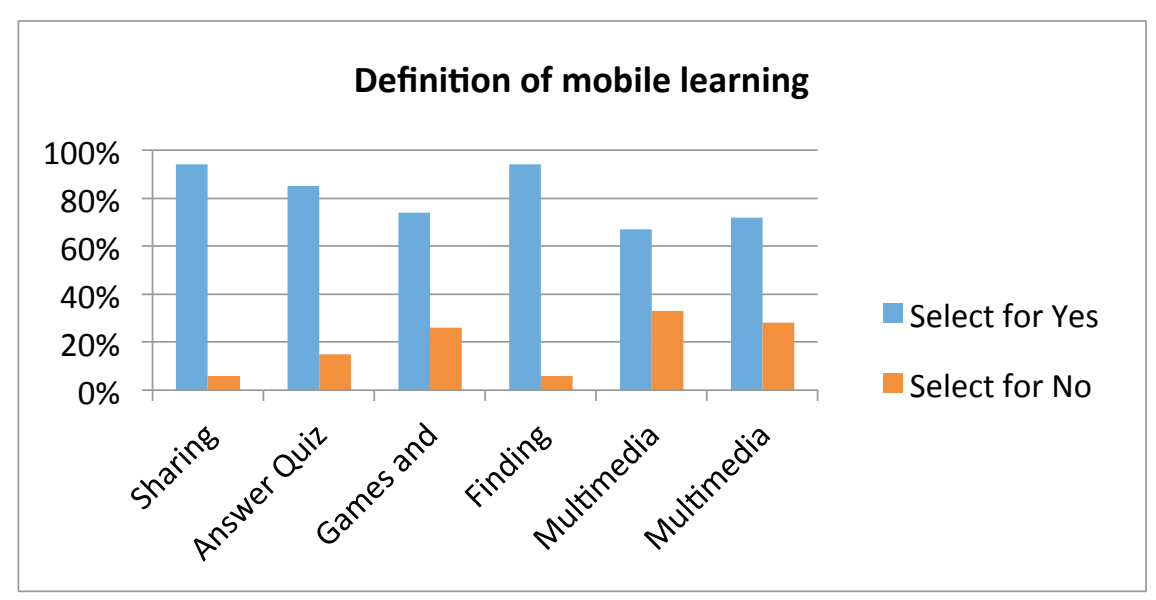

Fig. 9. Before student-generated (Select YES or NO)

Table 2. Mobile phone used during informal learning

\begin{tabular}{|c|c|c|c|c|c|c|}
\hline \multicolumn{7}{|c|}{ Mobile phone used during Informal Learning } \\
\hline Criteria & Never (1) & Rarely (2) & Sometimes (3) & Regularly (4) & Always (5) & Mean \\
\hline Record Audio & 18 & 72 & 129 & 52 & 85 & 2.80 \\
\hline Record Video & 16 & 72 & 138 & 40 & 95 & 2.84 \\
\hline Take Photo & 4 & 54 & 132 & 64 & 180 & 3.42 \\
\hline Edit Video & 27 & 92 & 96 & 56 & 40 & 2.45 \\
\hline Edit Audio & 36 & 80 & 99 & 48 & 30 & 2.31 \\
\hline Edit Photo & 10 & 66 & 132 & 72 & 110 & 3.07 \\
\hline
\end{tabular}


Paper-A Preliminary Investigation of Malaysian Student's Daily Use of Mobile Devices as Potenti...

Table 3. Which one do you always do for your existing formal learning with mobile phones

\begin{tabular}{|l|c|c|c|c|c|c|}
\hline \multicolumn{7}{|c|}{ Mobile phones during formal learning } \\
\hline \multicolumn{1}{|c|}{ Criteria } & Never (1) & Rarely (2) & Sometimes (3) & Regularly (4) & Always (5) & Mean (M) \\
\hline Record Audio & 22 & 66 & 123 & 52 & 90 & 2.78 \\
\hline Record Video & 18 & 62 & 141 & 60 & 80 & 2.84 \\
\hline Take Photo & 8 & 32 & 168 & 60 & 170 & 3.45 \\
\hline Edit Video & 29 & 76 & 111 & 56 & 40 & 2.46 \\
\hline Edit Audio & 33 & 78 & 108 & 52 & 30 & 2.37 \\
\hline Edit Photo & 16 & 66 & 150 & 44 & 100 & 2.96 \\
\hline
\end{tabular}

\section{Discussion}

Students reported that they used mobile phones for daily use, which can involve informal and formal learning. In addition, these daily activities also have the potential to add meaningful value to learning STEM from student-generated activities, such as lifelong learning.

\subsection{Potential for mobile learning for STEM in a Local University}

Mobile phones are used for personal use due to their affordability for daily tasks and activities. Hence, exploiting the use of mobile phones could potentially benefit both academics and students due to their meaningful value for educational purposes. Since participants have been using the multimedia functionality of mobile phones for daily use, it could also be applied for learning purposes for STEM. Even though some students used the multimedia content for learning they were unaware of its potential for the various types of mobile learning. For the participants, their earlier perceptions of mobile learning focused more on communication, such as SMS and phone calls. Hence, this demonstrates the potential to adopt wider mobile learning types in using multimedia functions for activities for STEM studies.

Challenges, such as limited ethical policies in the classroom were raised by the participants. There were also requirements for standard mobile phones for learning. In addition, the participants requested a standard mobile phone for learning to be adopted by their educational institutions. Other main issues were the lack of local content for mobile applications; technical issues, such as wireless coverage; lack of training; and the cost of the smartphones. Thus, these challenges need to be overcome to ensure that mobile learning can happen. Although some students reported using their own mobile devices for educational purposes, they were unaware that this was the Bring Your Own Device (BYOD) approach; furthermore, no guidelines had been prepared for implementation. Students requested a standard mobile device for learning purposes, which could lead to better implementation for mobile learning. 


\section{Conclusion}

This study focused on obtaining descriptive perspectives of firsthand users, i.e., students. The insights from this study indicate that students already have some awareness in terms of mobile learning from their daily activities [3]. However, challenges occurred due to technical problems, such as wireless, and the lack of ethical guidelines for educational purposes. Additionally, this study highlighted the informal daily usage and also formal educational purposes for mobile learning. Students have developed some skills using the multimedia functions of the mobile phones, which could be applied in STEM subjects for student-generated activities.

\section{References}

[1] Ariffin S. A. (2014), The Contribution of mobile learning to the Study of Local Culture in the Malaysian University Context, PhD dissertation, Faculty of Engineering and Information Technology, University of Technology Sydney, Sydney, Australia.

[2] Ariffin, S.A., Dyson, L.E., \& Hoskins-McKenzie, D. (2012). Content is King: Malaysian Industry Experts' Point of View on Local Content for Mobile Phones. Journal of Mobile Technologies, Knowledge \& Society, 2012 (2012), 1-9.

[3] Ariffin, S. A. (2016). Investigating the daily use of mobile phones as tools to enhance mobile learning for local cultural subjects in the context of Malaysian universities.

[4] Crompton, H., \& Traxler, J. (Eds.). (2016). Mobile Learning and STEM: Case Studies in Practice. Routledge.

[5] Deriquito, M., \& Domingo, Z. (2012). Mobile learning for teachers in Asia: exploring the potential of mobile technologies to support teachers and improve practice. UNESCO, Paris, France, Retrieved January 1, 2016 from http://unesdoc.unesco.org/images/0021/00216 2/216284E.pdf.

[6] Dyson, L.E. (2012). Student-generated mobile learning: A shift in the educational paradigm for the 21 st century. anzMLearn Transactions on Mobile Learning, 1(1), 5-19.

[7] Embi, M. A., \& Nordin, N. M. (2013). Mobile learning: Malaysian initiatives and research findings. Malaysia: Centre for Academic Advancement, Universiti Kebangsaan Malaysia, $1-131$.

[8] Hussin, S., Manap, M.R., Amir, Z., \& Krish, P. (2012). Mobile learning readiness among Malaysian students at higher learning institutes. Asian Social Science, 8(12), 276-283. https://doi.org/10.5539/ass.v8n12p276

[9] ukulska-Hulme, A., \& Traxler, J. (2007). Designing for mobile and wireless learning. Rethinking pedagogy for a digital age: Designing and delivering e-learning, 180-192.

[10] Kukulska-Hulme, A., Traxler, J. \& Pettit, J. (2007), 'Designed and user-generated activity in the mobile age', Journal of Learning Design, vol. 2, no. 1, pp. 52-65. https://doi.org/10.5204/jld.v2i1.28

[11] Labov, J. B., Reid, A. H., \& Yamamoto, K. R., Integrated biology and undergraduate science education: a new biology education for the twenty-first century? CBE-Life Sciences Education, 2010, 9(1), 10-16. https://doi.org/10.1187/cbe.09-12-0092

[12] Malaysia Education Blueprint 2013-2015 (2015). STEM Education: Policies and Prospects towards Avieveing International Standard and Meeting National Development Needs.

[13] Motlik, S. (2008). Mobile learning in developing nations. The International Review of Research in Open and Distributed Learning, 9(2). https://doi.org/10.19173/irrodl.v9i2.564 
Paper-A Preliminary Investigation of Malaysian Student's Daily Use of Mobile Devices as Potenti...

[14] Rancangan Malaysia Kesepuluh (RMK10). (2010) retrieved from: http://www.epu.gov. $\mathrm{my} / \mathrm{ms} / \mathrm{rmk} /$ rancangan-malaysia-kesepuluh.

[15] Rancangan Malaysia Kesebelas (RMK11). (2015) retrieved from: http://epu.gov. $\mathrm{my} / \mathrm{ms} / \mathrm{rmk} /$ rancangan-malaysia-kesebelas-2016-2020.

[16] Sanders, M., STEM, STEM education, STEM mania. The Technology Teacher, 2009, 20, 20-26.

[17] Sharples, M., Taylor, J., \& Vavoula, G. (2010). A theory of learning for the mobile age. In Medienbildung in neuen Kulturräumen (pp. 87-99). VS Verlag für Sozialwissenschaften. https://doi.org/10.1007/978-3-531-92133-4_6

[18] Silverman, D. (2013). Doing qualitative research: A practical handbook. London: SAGE Publications Limited.

[19] So, H.J. (2012). Turning on mobile learning in Asia: Illustrative initiatives and policy implications. In S. Vosloo \& M. West (Eds.), Policy focus: UNESCO working paper series on mobile learning (Vol. 1). Paris: UNESCO.

[20] Song, H.S.Y., Murphy, A., \& Farley, H. (2013) Mobile devices for learning in Malaysia: Then and now. Proceedings of the 30th Ascilite Conference, 830-34. 1-4 December 2013, Macquarie University, Sydney.

[21] SKMM Guidelines (2012). Content code, SKMM, Malaysia, Retrieved January 2, 2013 from http://www.skmm.gov.my/Resources/Guidelines/Content-Code.aspx.

[22] Traxler, J. (2011) Learning in a mobile age, a more and more mobile age. In combining eLearning and m-Learning: New applications of blended educational Resource, IGI Global, pp. 15-27. https://doi.org/10.4018/978-1-60960-481-3.ch002

[23] Traxler, J., Crompton, H. (2016) Mobile Learning and STEM: Case Studies in Practice, Routledge, doi: 10.4324/9781315745831, 2016. https://doi.org/10.4324/9781315745831

\section{$7 \quad$ Authors}

Shamsul Arrieya Ariffin, Salman Firdaus Side, and Mohd Fadhil Harfiez Mutalib are with Sultan Idris Education University, Tanjung Malim, Malaysia.

Article submitted 23 November 2017. Final cceptance 21 January 2018. Final version published as submitted by the authors. 